\title{
Histological type-specific prognostic factors of cervical small cell neuroendocrine carcinoma, adenocarcinoma, and squamous cell carcinoma
}

This article was published in the following Dove Press journal:

OncoTargets and Therapy

I July 2014

Number of times this article has been viewed

\section{Suthida Intaraphet ${ }^{1}$ \\ Nongyao Kasatpibal ${ }^{2}$ \\ Mette Søgaard ${ }^{3}$ \\ Surapan Khunamornpong ${ }^{4}$ \\ Jayanton Patumanond ${ }^{5}$ \\ Anchalee Chandacham ${ }^{6}$ \\ Imjai Chitapanarux ${ }^{7}$ \\ Sumalee Siriaunkgul ${ }^{4}$}

'Boromarajonani College of Nursing, KhonKaen, Thailand and Clinical Epidemiology Unit, Faculty of Medicine, Chiang Mai University, Chiang Mai, Thailand; ${ }^{2}$ Faculty of Nursing, Chiang Mai University, Chiang Mai, Thailand; ${ }^{3}$ Department of Clinical Epidemiology, Institute of Clinical Medicine, Aarhus University Hospital, Aarhus, Denmark; ${ }^{4}$ Department of Pathology, Faculty of Medicine, Chiang Mai University, Chiang Mai, Thailand; ${ }^{5} \mathrm{Clinical}$

Research Center, Faculty of Medicine, Thammasat University, PathumThani, Thailand; ' Department of Gynecology and Obstetrics, Nakornping Hospital, Chiang Mai, Thailand; ${ }^{7}$ Department of Radiology, Faculty of Medicine, Chiang Mai University, Chiang Mai, Thailand

Correspondence: Sumalee Siriaunkgul Department of Pathology, Faculty of Medicine, Chiang Mai University,

Chiang Mai 50200, Thailand

Tel +66539454424

Fax +66 53217 I44

Email sumalee.cmu@gmail.com
Background: The study aimed to determine the prognostic impact of clinical and pathological factors on survival among patients with small cell neuroendocrine carcinoma (SNEC), adenocarcinoma (ADC), and squamous cell carcinoma (SCC).

Methods: Eligible participants were all patients with histologically confirmed cervical cancer treated at Chiang Mai University Hospital between 1995 and 2011. We included all patients with SNEC and randomly enrolled patients with ADC and SCC. We used competing-risk regression analysis to examine the risk of cancer-related death by histological type.

Results: We included 130 (6.2\%) women with SNEC, 346 (16.4\%) with ADC, and 1,632 (77.4\%) with SCC. Age $>60$ years (hazard ratio [HR] 4.9, 95\% confidence interval [CI] 2.0-12.0) and lymph node involvement (HR 3.0, 95\% CI 1.2-7.4) were prognostic factors among surgicallytreated patients with SNEC. Deeper stromal invasion (HR 3.6, 95\% CI 1.6-8.3) was a prognostic factor in patients with SCC. In patients with advanced SNEC, age $>60$ years had a strong prognostic impact (HR 2.6, 95\% CI 1.0-6.5) while the International Federation of Gynecology and Obstetrics stages III and IV were prognostic factors for patients with advanced stage ADC (HR 2.9, 95\% CI 2.0-4.4 and HR 4.5, 95\% CI 2.6-7.9, respectively) and SCC (HR 1.7, 95\% CI 1.4-2.0 and HR 3.7, 95\% CI 2.8-4.9, respectively) compared with the International Federation of Gynecology and Obstetrics stage IIB.

Conclusion: Clinical and pathological prognostic factors in cervical cancer differed according to histological type. Taking the important prognostic factors for each histological type into consideration may be beneficial for tailored treatment and follow-up planning.

Keywords: prognosis, cervical cancer, histology, competing risk, survival, prognostic factor

\section{Introduction}

Cervical cancer is the third most common female cancer and the fourth leading cause of cancer death in women worldwide. ${ }^{1}$ About 529,800 new cases and approximately 275,100 deaths occurred in 2008. Of these, more than $85 \%, 453,300$ cases and 242,200 deaths, occurred in developing countries, including Thailand. ${ }^{1}$ In fact, cervical cancer was the second most common cancer among Thai women in 2011, accounting for $14.4 \%$ of all female cancers ${ }^{2}$ with an age-standardized mortality rate of 9.7 per 100,000 among Thai women in 2012. ${ }^{3}$

Histologically, squamous cell carcinoma (SCC) and adenocarcinoma (ADC) are the two most common subtypes, whereas small cell neuroendocrine carcinoma (SNEC) is an uncommon but aggressive subtype associated with poor survival compared with SCC and ADC. ${ }^{4-6}$ In addition to histological types, several potential prognostic factors including age, ${ }^{7-9}$ the International Federation of Gynecology and Obstetrics (FIGO) stage, ${ }^{10-12}$ tumor size, ${ }^{7,10,13}$ lymphovascular space invasion (LVSI), ${ }^{14}$ lymph

submit your manuscript | www.dovepress.coin 
node involvement, ${ }^{7,14-17}$ number of positive nodes, ${ }^{13,18}$ depth of stromal invasion, ${ }^{19}$ parametrial invasion, ${ }^{7,14,16,18,20}$ and treatment modality ${ }^{5,12,16,21}$ have been shown to influence survival, though not in all studies. ${ }^{22-24}$

Knowledge of potential prognostic factors is important for optimal selection of treatment modality, monitoring treatment response, and planning of follow-up. Although there is a large body of literature on prognostic factors of cervical cancer, we are unaware of studies examining the magnitudes of prognostic factors according to histological type among patients with SNEC, ADC, and SCC. Therefore, the aim of this cohort study was to determine the association between clinicopathological factors and survival of patients with SNEC, ADC, and SCC treated at a university hospital setting in Thailand over a 16-year period.

\section{Materials and methods}

\section{Setting and study population}

After approval from the ethics review board, we conducted this cohort study at Chiang Mai University Hospital, Thailand, which has 1,400 beds and serves an average of 1,000,000 outpatients and 50,000 in-patients annually. Eligible participants were patients with histologically confirmed cervical cancer who were diagnosed and treated at Chiang Mai University Hospital between January 1995 and October 2011. We included all patients with SNEC because of its rarity and randomly enrolled patients with ADC and SCC. We imitated the distribution of SCC and ADC by enrolling a proportion of SCC patients that was approximately five times greater than that of $\mathrm{ADC}$ into the cohort. We used the standard morphologic criteria ${ }^{25}$ for the diagnosis of SNEC based on a consensus agreement of two gynecologic pathologists. We used immunohistochemical stains for neuroendocrine markers (chromogranin, synaptophysin, or CD56) to confirm the morphologic diagnosis. Using the criteria by Roman et al, ${ }^{26}$ we identified LVSI based on hematoxylin and eosin staining, with exclusion of equivocal results. A gynecologic pathologist reexamined available histopathologic slides in cases where the pathological data was incomplete.

\section{Data on covariates}

\section{and treatment guidelines}

We extracted clinical and pathological data from medical, pathological, and cancer-registry reports and databases. We obtained dates of patient death from the medical records and/or the registry of the Thai Ministry of Interior. The study outcome was cancer-related death. Cancer-specific survival was defined as the time from the date of treatment to the date of cancer-related death, last follow-up, or censoring, whichever came first.
We used FIGO staging criteria ${ }^{27}$ for clinical stage in all patients. We defined early stage as FIGO stages I to IIA and advanced stage as stages IIB to IVB. We commonly performed primary radical hysterectomy and pelvic lymphadenectomy among patients with early stage of disease according to treatment guidelines in our hospital. Patients whose operative schedule was longer than 1 month from the date of operation scheduling also received neoadjuvant chemotherapy with triweekly cisplatin at a dosage of $75 \mathrm{mg} / \mathrm{m}^{2}$. Due to the aggressiveness of SNEC, patients with SNEC particularly received cisplatin plus etoposide instead of cisplatin alone (at a dosage of $75 \mathrm{mg} / \mathrm{m}^{2}$ for cisplatin and $100 \mathrm{mg} / \mathrm{m}^{2}$ for etoposide) and subsequently every 3 weeks for six courses after surgery. Further individualized adjuvant therapy was commonly considered according to the pathological findings after surgery, which included the following high-risk factors: lymph node involvement, parametrial invasion, and positive surgical margin, and the following intermediate-risk factors: deep stromal invasion, tumor size $>4 \mathrm{~cm}$, and LVSI more than ten spaces. Cisplatin-based was the first-line drug generally administrated to both patients receiving adjuvant chemoradiation therapy and adjuvant chemotherapy alone. Adjuvant chemoradiation therapy was given to patients who had either one of the high-risk pathological factors or at least two intermediate-risk factors, with weekly cisplatin at $40 \mathrm{mg} / \mathrm{m}^{2}$, except for patients with SNEC who still required etoposide plus cisplatin regimen. Triweekly cisplatin at $75 \mathrm{mg} / \mathrm{m}^{2}$ for four courses was administrated to patients who required adjuvant chemotherapy alone, such as patients with LVSI more than ten spaces only. Radiation therapy with or without chemotherapy was usually given to patients with advanced cancer stage. Patients who either had poor performance status or refused chemotherapy received radiation therapy alone.

\section{Statistical analysis}

We performed all statistical analyses using STATA software, version 11 (StataCorp LP, College Station, TX, USA). The differences among categorical variables according to histological type were assessed with exact probability test, and analysis of variance, Kruskal-Wallis or median test, as appropriate, for continuous variables. Treating noncancer-related death as a competing cause of death, we computed hazard ratios (HRs) with $95 \%$ confidence intervals (95\% CIs) using the Fine and Gray mode ${ }^{28}$ for competing-risk regression in both univariable and multivariable analyses. Prognostic factors with $P$-values $<0.25$ in the univariable analyses were included in the multivariable analyses. We estimated adjusted cancer-specific survival curves from cumulative incidence curves in the multivariable model. 
As data on pathological risk factors were only obtained in surgically-treated patients, we conducted analyses restricted to surgically-treated patients with early cancer stage and analyses stratified by cancer stage. The variables included in the analyses were age at diagnosis, FIGO stage, tumor size, LVSI, parametrial invasion, depth of stromal invasion, lymph node involvement, and treatment. All tests were two-tailed and we considered $P$-values of less than 0.05 as statistically significant.

\section{Results}

\section{Patient characteristics}

We included a sample of 2,108 women with cervical cancer over the 16-year study period. Of these, 130 (6.2\%) had SNEC, 346 (16.4\%) had ADC, and 1,632 (77.4\%) had SCC. Patients with SNEC were younger (mean age 43.3 years, standard deviation $[\mathrm{SD}] \pm 10.9)$ than those with ADC (mean age 49.3 years, $\mathrm{SD} \pm 10.3$ ) and SCC (mean age 52.4 years, $\mathrm{SD} \pm 12.1)$ and were more frequently diagnosed with early cancer stage $(63.1 \%$ for SNEC versus $28.9 \%$ for ADC and $26.5 \%$ for SCC). Surgically-treated patients with SNEC had a higher proportion of all pathological risk factors than those with ADC and SCC, and those with SCC had a higher proportion of some pathological risk factors compared with ADC (Table 1). Surgically-treated patients with SNEC were also more likely to receive adjuvant chemotherapy $(54.3 \%)$ than patients with ADC (4.7\%) and SCC (4.9\%).

Table I Clinical and pathological characteristics of patients with cervical small cell neuroendocrine carcinoma, adenocarcinoma, and squamous cell carcinoma

\begin{tabular}{|c|c|c|c|c|}
\hline Characteristic & $\begin{array}{l}\text { Small cell } \\
\text { neuroendocrine } n(\%)\end{array}$ & $\begin{array}{l}\text { Adenocarcinoma } \\
\text { n (\%) }\end{array}$ & $\begin{array}{l}\text { Squamous cell } \\
\text { carcinoma } \mathrm{n}(\%)\end{array}$ & $P$-value \\
\hline Overall & $130(6.2)$ & $346(16.4)$ & $\mathrm{I}, 632(77.4)$ & \\
\hline \multicolumn{5}{|l|}{ Age at diagnosis (years) } \\
\hline$<45$ & $73(56.2)$ & $118(34.1)$ & $461(28.3)$ & \\
\hline $45-60$ & $46(35.4)$ & $178(5 \mid .4)$ & $758(46.4)$ & \\
\hline$>60$ & II (8.4) & $50(14.5)$ & $413(25.3)$ & \\
\hline Mean $( \pm S D)$ & $44.3( \pm 10.9)$ & $49.3( \pm 10.3)$ & $52.4( \pm 12.1)$ & $<0.001$ \\
\hline \multicolumn{5}{|l|}{ FIGO stage } \\
\hline \multicolumn{5}{|l|}{ Early stage } \\
\hline I & $7 \mathrm{l}(54.6)$ & $92(26.6)$ & $349(21.4)$ & $<0.001$ \\
\hline$\| A$ & II (8.5) & $8(2.3)$ & $84(5.1)$ & \\
\hline \multicolumn{5}{|l|}{ Advanced stage } \\
\hline IIB & $26(20.0)$ & $100(28.9)$ & $448(27.5)$ & \\
\hline III & $16(12.3)$ & $95(27.5)$ & $558(34.2)$ & \\
\hline IV & $6(4.6)$ & $51(14.7)$ & $193(11.8)$ & \\
\hline \multicolumn{5}{|l|}{ Treatment } \\
\hline Surgery alone & $6(4.6)$ & $61(17.6)$ & $198(12.1)$ & $<0.001$ \\
\hline Surgery + any adjuvant therapy & $66(50.8)$ & $25(7.2)$ & $127(7.8)$ & \\
\hline CCRT & $30(23.1)$ & $116(33.5)$ & $469(28.7)$ & \\
\hline RT & $26(20.0)$ & $128(36.9)$ & $788(48.3)$ & \\
\hline CT & $2(1.5)$ & $16(4.6)$ & $50(3.1)$ & \\
\hline Tumor size $(\mathrm{cm})$ & $(\mathrm{n}=70 *)$ & $\left(\mathrm{n}=85^{*}\right)$ & $\left(n=325^{*}\right)$ & \\
\hline$<4$ & $55(78.6)$ & $74(87.1)$ & $298(91.7)$ & \\
\hline$\geq 4$ & $15(21.4)$ & $11(12.9)$ & $27(8.3)$ & \\
\hline Median (IQR) & $2(1.0-3.5)$ & $2(0.8-3.0)$ & I.3 (0.4-2.7) & 0.011 \\
\hline \multicolumn{5}{|l|}{ LVSI } \\
\hline Negative & $22(31.4)$ & $51(60.0)$ & I $78(54.8)$ & 0.001 \\
\hline Positive & $48(68.6)$ & $34(40.0)$ & 147 (45.2) & \\
\hline \multicolumn{5}{|l|}{ Parametrial invasion } \\
\hline Negative & $58(82.9)$ & $81(95.3)$ & $277(85.2)$ & 0.020 \\
\hline Positive & $12(17.1)$ & $4(4.7)$ & $48(14.8)$ & \\
\hline \multicolumn{5}{|l|}{ Depth of stromal invasion } \\
\hline Inner to middle $1 / 3$ & 37 (52.9) & $57(67.1)$ & $210(64.6)$ & 0.138 \\
\hline Outer $1 / 3$ & $33(47.1)$ & $28(32.9)$ & $115(35.4)$ & \\
\hline \multicolumn{5}{|l|}{ Lymph node involvement } \\
\hline Negative & $56(80.0)$ & $75(88.2)$ & $266(81.9)$ & 0.299 \\
\hline Positive & $14(20.0)$ & $10(11.8)$ & $59(18.1)^{\prime}$ & \\
\hline
\end{tabular}

Note: *Data on pathological risk factors were obtained from patients undergoing surgery as primary treatment only.

Abbreviations: CCRT, concurrent chemoradiation therapy; CT, chemotherapy; FIGO, International Federation of Gynecology and Obstetrics; IQR, interquartile range; LVSI, lymphovascular space invasion; RT, radiation therapy; SD, standard deviation. 


\section{Prognostic factors according to histological type}

Surgically-treated patients with early cancer stage

Five-year cancer-specific survival among patients with early stage was $64.0 \%$ for SNEC, $90.3 \%$ for ADC, and $88.1 \%$ for SCC. The 10 -year cancer-specific survival among surgically-treated patients was $56.3 \%$ for patients with SNEC, $93.2 \%$ for ADC, and $89.7 \%$ for SCC. Among surgically-treated patients with SNEC and ADC, we found better 10-year survival rates in patients receiving adjuvant chemotherapy ( $70.3 \%$ and $100 \%$, respectively) compared with surgery alone (55.6\% and $96.2 \%$, respectively), adjuvant radiation therapy (37.5\% and $83.3 \%$, respectively), and adjuvant chemoradiation therapy $(30.1 \%$ and $82.5 \%$, respectively), with $P=0.032$ for SNEC and $P=0.182$ for ADC. Among surgically-treated patients with SCC, those who underwent surgery alone showed a better 10 -year survival rate of $95.3 \%$ compared with $87.5 \%$ for those receiving adjuvant chemotherapy, $82.0 \%$ for adjuvant radiation therapy, and $77.1 \%$ for adjuvant chemoradiation therapy $(P=0.001)$.

Univariable analyses of surgically-treated patients showed that depth of stromal invasion and lymph node involvement were significant prognostic factors regardless of histological type (Table 2). Because there were very few cancer-related deaths among surgically-treated patients with ADC (only five of 85 women), multivariable analysis could only be performed for patients with SNEC and SCC as shown in Table 3. Adjusted cancer-specific survival curves for significant prognostic factors among surgically-treated patients with SNEC and SCC are shown in Figure 1.

\section{Patients with advanced cancer stage}

Five-year cancer-specific survival in patients with advanced stage was $18.0 \%, 39.1 \%$, and $49.7 \%$ for patients with SNEC, $\mathrm{ADC}$, and SCC, respectively. In univariable analysis, age $>60$ years, FIGO stage IV, and chemotherapy were

Table 2 Univariable analysis of clinical and pathological prognostic factors in surgically-treated patients with cervical cancer according to histological type

\begin{tabular}{|c|c|c|c|c|c|c|}
\hline \multirow[t]{2}{*}{ Characteristic } & \multicolumn{2}{|c|}{$\begin{array}{l}\text { Small cell neuroendocrine } \\
(\mathrm{n}=70)\end{array}$} & \multicolumn{2}{|c|}{$\begin{array}{l}\text { Adenocarcinoma } \\
(n=85)\end{array}$} & \multicolumn{2}{|c|}{$\begin{array}{l}\text { Squamous cell carcinoma } \\
(n=325)\end{array}$} \\
\hline & HR (95\% Cl) & $P$-value & HR $(95 \% \mathrm{Cl})$ & $P$-value & HR (95\% Cl) & $P$-value \\
\hline \multicolumn{7}{|l|}{ Age at diagnosis (years) } \\
\hline$<45$ & $2.3(0.9-6.1)$ & 0.096 & $2.3(0.2-21.4)$ & 0.476 & $0.7(0.3-1.5)$ & 0.335 \\
\hline $45-60$ & Reference & - & Reference & - & Reference & - \\
\hline$>60$ & $5.8(2.4-13.9)$ & $<0.001$ & $7.4(0.6-96.4)$ & 0.128 & I.I (0.2-4.7) & 0.925 \\
\hline \multicolumn{7}{|l|}{ FIGO stage } \\
\hline I & Reference & - & Reference & - & Reference & - \\
\hline$\| \mathrm{A}$ & I.3 (0.3-5.5) & 0.717 & $3.7(0.8-18.2)$ & 0.102 & $2.9(1.3-6.8)$ & 0.013 \\
\hline \multicolumn{7}{|l|}{ Tumor size $(\mathrm{cm})$} \\
\hline$<4$ & Reference & - & Reference & - & Reference & - \\
\hline$\geq 4$ & $1.9(0.7-5.1)$ & 0.173 & $1.8(0.2-14.9)$ & 0.592 & $0.9(0.2-3.7)$ & 0.870 \\
\hline \multicolumn{7}{|l|}{ LVSI } \\
\hline Negative & Reference & - & Reference & - & Reference & - \\
\hline Positive & $1.9(0.8-4.6)$ & 0.171 & $4.1(1.6-10.8)$ & 0.004 & $3.1(1.5-6.4)$ & 0.002 \\
\hline \multicolumn{7}{|l|}{ Parametrial invasion } \\
\hline Negative & Reference & - & Reference & - & Reference & - \\
\hline Positive & $1.5(0.6-4.1)$ & 0.414 & $7.9(0.9-74.0)$ & 0.068 & $3.1(1.4-6.8)$ & 0.004 \\
\hline \multicolumn{7}{|c|}{ Depth of stromal invasion } \\
\hline Inner to middle $\mathrm{I} / 3$ & Reference & - & Reference & - & Reference & - \\
\hline Outer $1 / 3$ & $3.1(1.3-7.2)$ & 0.009 & $9.1(1.2-82.6)$ & 0.049 & $6.1(2.9-12.9)$ & $<0.001$ \\
\hline \multicolumn{7}{|c|}{ Lymph node involvement } \\
\hline Negative & Reference & - & Reference & - & Reference & - \\
\hline Positive & $4.3(2.0-9.1)$ & $<0.001$ & $6.5(I . I-36.8)$ & 0.036 & $3.0(1.4-6.3)$ & 0.003 \\
\hline \multicolumn{7}{|l|}{ Primary treatment } \\
\hline Surgery alone & Reference & - & Reference & - & Reference & - \\
\hline $\begin{array}{l}\text { Surgery plus any } \\
\text { adjuvant therapy* }\end{array}$ & I.2 (0.3-4.9) & 0.782 & $4.3(0.7-24.9)$ & 0.108 & 4.I (2.0-8.6) & $<0.001$ \\
\hline
\end{tabular}

Note: *Adjuvant therapy: radiation therapy, chemotherapy, and concurrent chemoradiation therapy.

Abbreviations: Cl, confidence interval; FIGO, International Federation of Gynecology and Obstetrics; HR, hazard ratio; LVSI, lymphovascular space invasion. 
Table 3 Multivariable analysis of clinical and pathological prognostic factors in surgically-treated patients with cervical cancer according to histological type

\begin{tabular}{|c|c|c|c|c|}
\hline \multirow[t]{2}{*}{ Characteristic } & \multicolumn{2}{|c|}{$\begin{array}{l}\text { Small cell neuroendocrine } \\
(n=70)\end{array}$} & \multicolumn{2}{|c|}{$\begin{array}{l}\text { Squamous cell carcinoma } \\
(n=325)\end{array}$} \\
\hline & HR (95\% Cl) & $P$-value & HR (95\% CI) & $P$-value \\
\hline Age at diagnosis (years) & & & Not included & \\
\hline$<45$ & $1.5(0.5-4.6)$ & 0.487 & in the analysis & - \\
\hline $45-60$ & Reference & - & & \\
\hline$>60$ & $4.9(2.0-12.0)$ & 0.001 & & \\
\hline FIGO stage & Not included & & & \\
\hline I & in the analysis & - & Reference & - \\
\hline$\| \mathrm{A}$ & & & $1.3(0.6-3.0)$ & 0.563 \\
\hline Tumor size $(\mathrm{cm})$ & & & Not included & \\
\hline$<4$ & Reference & - & in the analysis & - \\
\hline$\geq 4$ & $1.2(0.4-3.3)$ & 0.706 & & \\
\hline \multicolumn{5}{|l|}{ LVSI } \\
\hline Negative & Reference & - & Reference & - \\
\hline Positive & $1.0(0.3-3.4)$ & 0.936 & $1.3(0.6-2.9)$ & 0.490 \\
\hline Parametrial invasion & Not included & & & \\
\hline Negative & in the analysis & - & Reference & - \\
\hline Positive & & & $1.0(0.4-3.0)$ & 0.968 \\
\hline \multicolumn{5}{|l|}{ Depth of stromal invasion } \\
\hline Inner to middle $1 / 3$ & Reference & - & Reference & - \\
\hline Outer $1 / 3$ & $2.0(0.9-4.6)$ & 0.113 & $3.6(1.6-8.3)$ & 0.002 \\
\hline \multicolumn{5}{|l|}{ Lymph node involvement } \\
\hline Negative & Reference & - & Reference & - \\
\hline Positive & $3.0(1.2-7.4)$ & 0.014 & $1.3(0.4-3.6)$ & 0.669 \\
\hline Primary treatment & Not included & & & \\
\hline Surgery alone & in the analysis & - & Reference & - \\
\hline $\begin{array}{l}\text { Surgery plus any } \\
\text { adjuvant therapy* }\end{array}$ & & & $1.7(0.6-4.7)$ & 0.317 \\
\hline
\end{tabular}

Note: *Adjuvant therapy: radiation therapy, chemotherapy, and concurrent chemoradiation therapy.

Abbreviations: $\mathrm{Cl}$, confidence interval; FIGO, International Federation of Gynecology and Obstetrics; HR, hazard ratio; LVSI, lymphovascular space invasion.

strongly associated with decreased survival regardless of histology (Table 4).

In multivariable analysis, age $>60$ years (HR 2.6, 95\% CI 1.0-6.5) and FIGO stage IV (HR 6.3, 95\% CI 0.9-43.4) were important prognostic factors for patients with advanced SNEC. Compared with FIGO stage IIB, FIGO stage III and IV were associated with poor survival among patients with advanced ADC (HR 2.9, 95\% CI 2.0-4.4 and HR 4.5, 95\% CI 2.6-7.9, respectively) and SCC (HR 1.7, 95\% CI 1.4-2.0 and HR 3.7, 95\% CI 2.8-4.9, respectively.) Age $>60$ years was borderline significant in patients with advanced SCC (HR 1.2, 95\% CI 0.9-1.5) compared with age 45-60 years (Table 4). Adjusted cancer-specific survival curves for significant prognostic factors in multivariable models among patients with advanced stage are depicted in Figure 2.

\section{Discussion}

Our cohort study revealed that clinical and pathological prognostic factors differed according to histological type in patients with cervical cancer. Patients with SNEC had the poorest prognosis in both early and advanced cancer stage compared with ADC and SCC.

Lymph node involvement and age at diagnosis $>60$ years had a significant impact on cancer-specific survival among surgically-treated patients with SNEC. In line with this, Boruta et $\mathrm{al}^{29}$ showed that lymph node involvement was a prognostic factor among patients with early stage SNEC treated by radical surgery and adjuvant chemotherapy. In contrast, a Taiwanese study of 116 surgically-treated patients with SNEC showed that lymph node involvement and age were not associated with survival. ${ }^{30}$ However, lymph node involvement had a strong prognostic impact for all 179 patients in that study, which included both patients receiving surgery and other treatments. Previous studies have shown advanced age, regardless of stage, is a poor prognostic factor in patients with SNEC. ${ }^{4,31}$ Similarly, our findings showed that age $>60$ years was the only significant prognostic factor among patients with advanced stage SNEC while FIGO stage IV showed a 
A

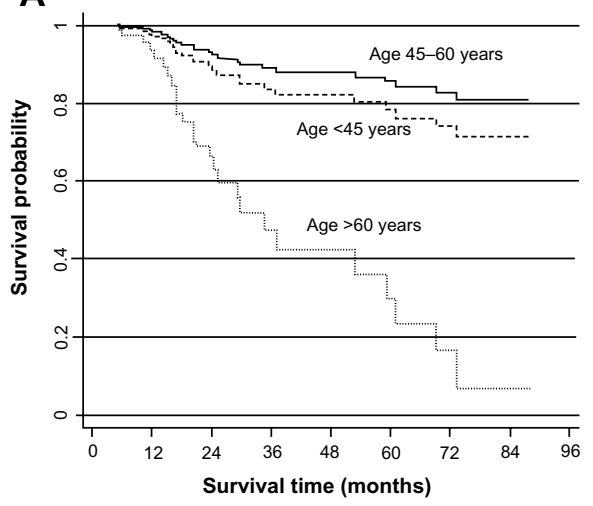

B

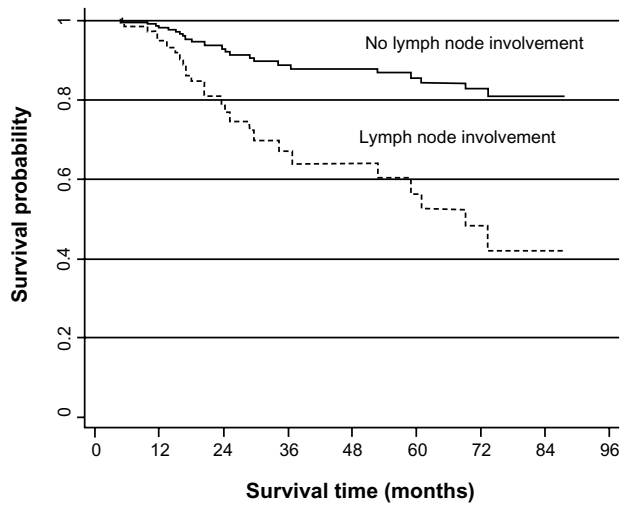

C

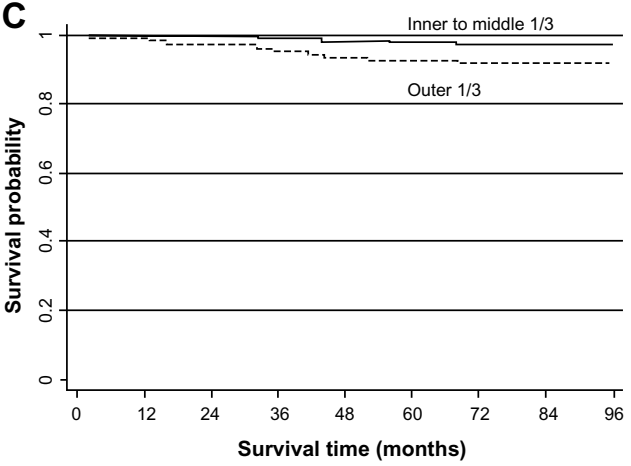

Figure I Adjusted cancer-specific survival in patients with early stage categorized by significant prognostic factors in multivariable analysis.

Notes: (A) Age at diagnosis in patients with SNEC adjusted for tumor size, LVSI, depth of stromal invasion, and lymph node involvement; (B) lymph node involvement in patients with SNEC adjusted for age at diagnosis, tumor size, LVSI, and depth of stromal invasion; (C) depth of stromal invasion in patients with SCC adjusted for FIGO stage, LVSI, parametrial involvement, lymph node involvement, and primary treatment.

Abbreviations: FIGO, International Federation of Gynecology and Obstetrics; LVSI, lymphovascular space invasion; SCC, squamous cell carcinoma; SNEC, small cell neuroendocrine carcinoma.

strong effect but was not statistically significant, most likely due to the small sample size of only six SNEC patients with FIGO stage IV in our study. Thus, similar to the Taiwanese study, and even though we included all patients with SNEC over a period of 16 years, the statistical precision for some of the estimates was still low. This may, in part, explain some of the discrepancy.

We noted a slightly better 10-year survival after surgery among patients with ADC compared with SCC. This may result from a lower proportion of pathological risk factors such as LVSI, parametrial involvement, deeper stromal invasion, and lymph node involvement. Likewise, Kasamatsu et $\mathrm{al}^{13}$ reported higher percentages of LVSI, deeper stromal invasion, larger tumor size, vaginal infiltration, and greater number of positive pelvic lymph nodes in FIGO stage I-IIB patients with ADC than those with SCC in their study. However, no significant difference in 5-year survival between ADC and SCC was observed in that study, with $89 \%, 92 \%$, and $38 \%$ in ADC patients with pathological stage pT1b, pT2a, and pT2b, respectively, versus $89 \%, 89 \%$, and $62 \%$ in SCC patients with pathological stage pT1b, pT2a, and pT2b, respectively. Among advanced ADC patients, our findings revealed a prognostic value of FIGO stage III and IV compared with FIGO stage IIB. Consistent with our results, prior studies reported significant impact of advanced FIGO stage on survival among patients with ADC,,$^{32-34}$ though two studies used FIGO stage I as a reference group. ${ }^{33,34}$

In surgically-treated SCC, deep stromal invasion was the only significant prognostic factor in our study. Consistently, a study that combined FIGO stage I-IIB SCC (445 patients) and ADC (123 patients) also revealed a prognostic impact of deeper stromal invasion on both overall and recurrence-free survival. ${ }^{13}$ In contrast, previous studies found no prognostic impact of deep stromal invasion while pelvic lymph node metastasis, parametrial involvement, and positive surgical margin were prognostic factors in patients with stage IA2-IIA SCC who underwent radical hysterectomy., ${ }^{7,35}$ FIGO stage III and IV were significant prognostic factors in advanced stage SCC in our results. Correspondingly, a study of cervical cancer patients with locally advanced stage including 66 women 


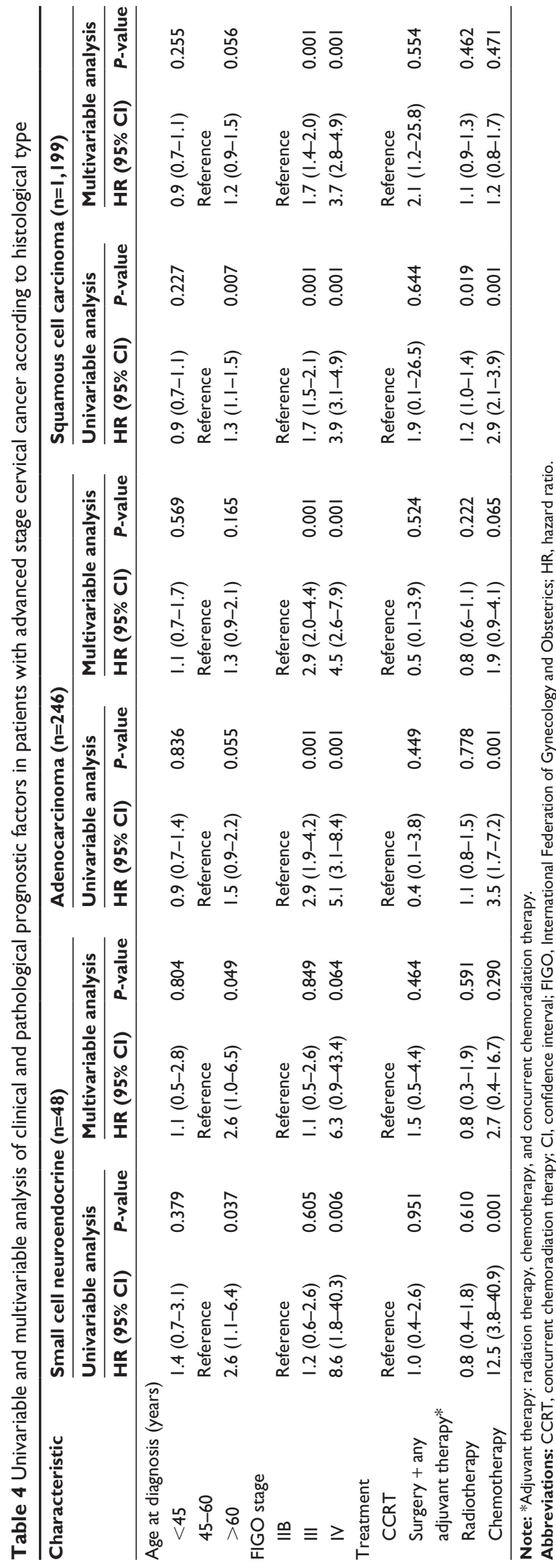

with SCC (93\%) and five women with ADC (7\%) found a significant poorer 5 -year overall survival among patients with FIGO stage III (77.0\%) and IVA (42.9\%) than those with FIGO stage IIB $(83.5 \%)(P=0.041) .{ }^{36}$ In contrast, another recent study of 125 women with locally advanced cervical cancer (105 [84\%] women with SCC, and 20 [16\%] women with ADC) demonstrated that, for the entire group, FIGO stage III was not associated with significantly decreased overall survival compared with FIGO stage I + II (HR 1.2, 95\% CI 0.4-3.4). ${ }^{37}$

Our study showed no significant prognostic difference in multivariable analyses among treatment modalities in both surgically-treated and advanced stage patients. In line with our findings, previous studies including patients with SCC, ADC, and adenosquamous carcinoma found no significant difference between radical hysterectomy with systematic lymphadenectomy alone and surgery plus postoperative adjuvant radiotherapy ${ }^{14,38}$ Another study of SNEC also found no significant benefit of radical surgery plus any adjuvant therapies over radical surgery alone among 94 surgically-treated early stage patients with SNEC (14 patients from authors' institute and 82 retrieved from prior studies).$^{39}$ However, the better 10 -year survival of surgically-treated SNEC and ADC patients with adjuvant chemotherapy compared with those treated by surgery alone and other adjuvant types may indicate a positive impact of adjuvant chemotherapy after surgery among these patients. In contrast to SNEC and ADC, we found a better 10-year survival in SCC patients with surgery alone compared with other adjuvant types. The reason for this better survival is unclear, but may be, at least in part, related to the fact that the patients who received any type of adjuvant therapies usually had a higher percentage of pathological risk factors or had greater disease extension than those receiving surgery alone. Thus, the better survival was observed among patients who received surgery alone. Moreover, SCC is considered as a less aggressive histological type that has not much adverse impact on patient survival. ${ }^{11}$ Although concurrent chemoradiation therapy (CCRT) is the standard treatment for locally advanced cervical cancer, our results showed no significant difference among CCRT and other treatment modalities in patients with advanced cancer stage. Likewise, a study among locally advanced SCC and ADC treatments in Thailand revealed no significant benefit of CCRT over radiotherapy alone. ${ }^{40}$

Strengths of our study include the relatively large number of patients with SNEC from a single institute. All patients were treated with uniform surgical techniques or treatment guidelines. In addition, all surgical pathological specimens were evaluated by gynecologic pathologists in our hospital. 



Figure 2 Adjusted cancer-specific survival in patients with advanced stage categorized by significant prognostic factors in multivariable analysis.

Notes: (A) Age at diagnosis in patients with SNEC adjusted for FIGO stage and treatment; (B) FIGO stage in patients with ADC adjusted for age at diagnosis and treatment; (C) FIGO stage in patients with SCC adjusted for age at diagnosis and treatment.

Abbreviations: ADC, adenocarcinoma; FIGO, International Federation of Gynecology and Obstetrics; SCC, squamous cell carcinoma; SNEC, small cell neuroendocrine carcinoma.

Limitations to our study include the retrospective design and the rather small number of patients and deaths among surgicallytreated patients with ADC. Therefore, the multivariable analysis could not be performed to confirm the association of prognostic factors among surgically-treated patients with ADC.

In conclusion, we reported that clinical and pathological prognostic factors in cervical cancer differed among histological type. Age $>60$ years and lymph node involvement had a strong prognostic impact in patients with SNEC. Deeper stromal invasion and FIGO stage were prognostic factors among patients with SCC while FIGO stage was a strong prognostic factor in advanced stage ADC. These important prognostic factors for each histological type may be beneficial for taking into consideration for tailored treatment and follow-up planning.

\section{Acknowledgments}

The authors acknowledge the National Research University Project under Thailand's Office of the Higher Education
Commission and The Graduate School, Chiang Mai University, Thailand for financial support.

\section{Disclosure}

The authors report no conflicts of interest in this work.

\section{References}

1. Jemal A, Bray F, Center MM, Ferlay J, Ward E, Forman D. Global cancer statistics. CA Cancer J Clin. 2011;61(2):69-90.

2. Attasara P, Buasom R. Hospital-based cancer registry 2011 [webpage on the Internet]. National Cancer Institute. Ministry of Public Health, Thailand; 2013 [cited September 25, 2013]. Available from: http://www.nci. go.th/th/File_download/Nci\%20Cancer\%20Registry/Hospitalbase2011. pdf. Accessed June 16, 2014.

3. GLOBOCAN 2012. Estimate cancer incidence, mortality, and prevalence worldwide in 2012. Rates: cancer by population [webpage on the Internet]; 2012 [cited June 10, 2014]. International Agency for Research on Cancer. Available from: http://globocan.iarc.fr/old/summary_table_pop-html.asp? selection $=194764 \&$ title $=$ Thailand\&sex $=2$ \& type $=1 \&$ window $=1 \&$ sort $=0 \&$ submit $=\% \mathrm{C} 2 \% \mathrm{~A} 0$ Execute $\% \mathrm{C} 2 \% \mathrm{~A} 0$. Accessed June 16, 2014.

4. Chen J, Macdonald OK, Gaffney DK. Incidence, mortality, and prognostic factors of small cell carcinoma of the cervix. Obstet Gynecol. 2008;111(6):1394-1402. 
5. Vinh-Hung V, Bourgain C, Vlastos G, et al. Prognostic value of histopathology and trends in cervical cancer: a SEER population study. BMC Cancer. 2007;7:164.

6. Intaraphet S, Kasatpibal N, Siriaunkgul S, et al. Prognostic impact of histology in patients with cervical squamous cell carcinoma, adenocarcinoma and small cell neuroendocrine carcinoma. Asian Pac J Cancer Prev. 2013;14(9):5355-5360.

7. Park JY, Kim DY, Kim JH, Kim YM, Kim YT, Nam JH. Outcomes after radical hysterectomy in patients with early-stage adenocarcinoma of uterine cervix. Br J Cancer. 2010;102(12):1692-1698.

8. Brewster WR, DiSaia PJ, Monk BJ, Ziogas A, Yamada SD, Anton-Culver H. Young age as a prognostic factor in cervical cancer: results of a population-based study. Am J Obstet Gynecol. 1999; 180(6 Pt 1):1464-1467.

9. Suprasert P, Srisomboon J, Siriaunkgul S, et al. Clinical outcomes and prognostic factors of node-negative cervical cancer patients with deep stromal invasion or lymphovascular space involvement following radical hysterectomy. J Med Assoc Thai. 2006;89(9):1368-1375.

10. Shingleton HM, Bell MC, Fremgen A, et al. Is there really a difference in survival of women with squamous cell carcinoma, adenocarcinoma, and adenosquamous cell carcinoma of the cervix? Cancer. 1995; 76(Suppl 10):1948-1955.

11. McCusker ME, Coté TR, Clegg LX, Tavassoli FJ. Endocrine tumors of the uterine cervix: incidence, demographics, and survival with comparison to squamous cell carcinoma. Gynecol Oncol. 2003;88(3): 333-339.

12. Lee JM, Lee KB, Nam JH, et al. Prognostic factors in FIGO stage IB-IIA small cell neuroendocrine carcinoma of the uterine cervix treated surgically: results of a multi-center retrospective Korean study. Ann Oncol. 2008;19(2):321-326.

13. Kasamatsu T, Onda T, Sawada M, et al. Radical hysterectomy for FIGO stage I-IIB adenocarcinoma of the uterine cervix. Br J Cancer. 2009;100(9):1400-1405.

14. Takeda N, Sakuragi N, Takeda M, et al. Multivariate analysis of histopathologic prognostic factors for invasive cervical cancer treated with radical hysterectomy and systematic retroperitoneal lymphadenectomy. Acta Obstet Gynecol Scand. 2002;81(12):1144-1151.

15. Lee DW, Kim YT, Kim JH, et al. Clinical significance of tumor volume and lymph node involvement assessed by MRI in stage IIB cervical cancer patients treated with concurrent chemoradiation therapy. J Gynecol Oncol. 2010;21(1):18-23.

16. Liu MT, Hsu JC, Liu WS, et al. Prognostic factors affecting the outcome of early cervical cancer treated with radical hysterectomy and post-operative adjuvant therapy. Eur J Cancer Care (Engl). 2008;17(2): 174-181.

17. Yan M, Zhang YN, He JH, Sun JR, Sun XM. Influence of lymph vascular space invasion on prognosis of patients with early-stage cervical squamous cell carcinoma. Chin J Cancer. 2010;29(4):425-430.

18. Aoki Y, Sasaki M, Watanabe M, et al. High-risk group in node-positive patients with stage IB, IIA, and IIB cervical carcinoma after radical hysterectomy and postoperative pelvic irradiation. Gynecol Oncol. 2000;77(2):305-309.

19. Ho CM, Chien TY, Huang SH, Wu CJ, Shih BY, Chang SC. Multivariate analysis of the prognostic factors and outcomes in early cervical cancer patients undergoing radical hysterectomy. Gynecol Oncol. 2004;93(2):458-464.

20. Huang L, Zheng M, Liu JH, et al. Risk factors and prognosis of IB-IIB cervical carcinoma with common iliac lymph node metastasis. Chin J Cancer. 2010;29(4):431-435

21. Kim HJ, Ha SW, Wu HG. Treatment outcomes and prognostic factors in uterine cervical cancer patients treated with postoperative extended field radiation therapy. J Gynecol Oncol. 2009;20(4):227-231.

22. Fregnani JH, Soares FA, Novik PR, Lopes A, Latorre MR. Comparison of biological behavior between early-stage adenocarcinoma and squamous cell carcinoma of the uterine cervix. Eur J Obstet Gynecol Reprod Biol. 2008;136(2):215-223.
23. Creasman WT, Kohler MF. Is lymph vascular space involvement an independent prognostic factor in early cervical cancer? Gynecol Oncol. 2004;92(2):525-529.

24. Allam M, Feely C, Millan D, Nevin J, Davis J, Siddiqui N. Depth of cervical stromal invasion as a prognostic factor after radical surgery for early stage cervical cancer. Gynecol Oncol. 2004;93(3): 637-641.

25. Albores-Saavedra J, Gersell D, Gilks CB, et al. Terminology of endocrine tumors of the uterine cervix: results of a workshop sponsored by the College of American Pathologists and the National Cancer Institute. Arch Pathol Lab Med. 1997;121(1):34-39.

26. Roman LD, Felix JC, Muderspach LI, et al. Influence of quantity of lymph-vascular space invasion on the risk of nodal metastases in women with early-stage squamous cancer of the cervix. Gynecol Oncol. 1998;68(3):220-225.

27. Pecorelli S. Revised FIGO staging for carcinoma of the vulva, cervix, and endometrium. Int J Gynaecol Obstet. 2009;105(2):103-104.

28. Fine JP, Gray RJ. A proportional hazards model for the subdistribution of a competing risk. J Am Stat Assoc. 1999;94(446):496-509.

29. Boruta DM, Schorge JO, Duska LA, Crum CP, Castrillon DH, Sheets EE. Multimodality therapy in early-stage neuroendocrine carcinoma of the uterine cervix. Gynecol Oncol. 2001;81(1):82-87.

30. Wang KL, Chang TC, Jung SM, et al. Primary treatment and prognostic factors of small cell neuroendocrine carcinoma of the uterine cervix: a Taiwanese Gynecologic Oncology Group study. Eur J Cancer. 2012;48(10):1484-1494.

31. Hoskins PJ, Swenerton KD, Pike JA, et al. Small-cell carcinoma of the cervix: fourteen years of experience at a single institution using a combined-modality regimen of involved-field irradiation and platinum-based combination chemotherapy. J Clin Oncol. 2003;21(18): 3495-3501.

32. Lea JS, Sheets EE, Wenham RM, et al. Stage IIB-IVB cervical adenocarcinoma: prognostic factors and survival. Gynecol Oncol. 2002;84(1):115-119.

33. Ishikawa H, Nakanishi T, Inoue T, Kuzuya K. Prognostic factors of adenocarcinoma of the uterine cervix. Gynecol Oncol. 1999;73(1): 42-46.

34. Baalbergen A, Ewing-Graham PC, Hop WC, Struijk P, Helmerhorst TJ. Prognostic factors in adenocarcinoma of the uterine cervix. Gynecol Oncol. 2004;92(1):262-267.

35. Xiong Y, Liang L, Peng X, Wei M, Shen Y. Prognostic factors for patients with FIGO stage-IB cervical squamous cell carcinoma: does the tumor size $(\leq 4 \mathrm{~cm}$ or $>4 \mathrm{~cm})$ really matter? Chin J Clin Oncol. 2007;4(2):115-120.

36. Yamashita H, Nakagawa K, Tago M, Shiraishi K, Nakamura N, Ohtomo K. Treatment results and prognostic analysis of radical radiotherapy for locally advanced cancer of the uterine cervix. $\mathrm{Br} J$ Radiol. 2005;78(933):821-826.

37. Chen CC, Wang L, Lin JC, Jan JS. The prognostic factors for locally advanced cervical cancer patients treated by intensity-modulated radiation therapy with concurrent chemotherapy. J Formos Med Assoc. In press 2012.

38. Turan T, Özer A, Boztosun A, et al. Multivariate analysis of prognostic factors in patients with stage IB cervical cancer who underwent radical hysterectomy. CMJ. 2010;32:303-314.

39. Tian WJ, Zhang MQ, Shui RH. Prognostic factors and treatment comparison in early-stage small cell carcinoma of the uterine cervix. Oncol Lett. 2012;3(1):125-130.

40. Katanyoo K, Sanguanrungsirikul S, Manusirivithaya S. Comparison of treatment outcomes between squamous cell carcinoma and adenocarcinoma in locally advanced cervical cancer. Gynecol Oncol. 2012;125(2):292-296. 


\section{Publish your work in this journal}

OncoTargets and Therapy is an international, peer-reviewed, open access journal focusing on the pathological basis of all cancers, potential targets for therapy and treatment protocols employed to improve the management of cancer patients. The journal also focuses on the impact of management programs and new therapeutic agents and protocols on

patient perspectives such as quality of life, adherence and satisfaction. The manuscript management system is completely online and includes a very quick and fair peer-review system, which is all easy to use. Visit http://www.dovepress.com/testimonials.php to read real quotes from published authors.

Submit your manuscript here: http://www.dovepress.com/oncotargets-and-therapy-journal 